\title{
The interaction between captured human thrombin and antithrombin studied by surface plasmon resonance, and the effect of melagatran
}

\author{
Susanne Elg and Johanna Deinum* \\ Department Cell Biology and Biochemistry, AstraZeneca R \& D, S 43183 Mölndal, Sweden
}

\begin{abstract}
The kinetics of the interactions between thrombin and antithrombin were studied by surface plasmon resonance. Although amine coupled thrombin binds low molecular weight active site inhibitors with a one-to-one stoichiometry hirudin only bound to $75 \%$ of the coupled active thrombin. However, antithrombin or thrombomodulin could not bind at all to aminecoupled thrombin. To make it possible to follow the reaction with antithrombin in time thrombin was therefore captured on an antibody against thrombin. Alternatively, antithrombin was captured on an antibody against antithrombin to follow complex formation with thrombin. With these techniques the second-order rate constant for the interaction of antithrombin with thrombin in the presence of heparin, was estimated to be $k_{\mathrm{a}} \geqslant 0.4 \times 10^{6} \mathrm{M}^{-1} \mathrm{~s}^{-1}$ with $K_{\mathrm{D}}=50 \mathrm{nM}$ for the formation of the initial complex. These values are similar to those found in solution. In the absence of heparin, the second-order rate constant for the interaction of thrombin with captured antithrombin was only $k_{\mathrm{a}}=9 \times 10^{3} \mathrm{M}^{-1} \mathrm{~s}^{-1}$. Thus, with this technique rate constants for the interaction of proteases with serpins can be determined in a convenient way, without the need for stopped-flow. The rapidbinding, active-site-directed thrombin inhibitor, melagatran, competed with the antithrombin-thrombin interaction. Although melagatran, a reversible thrombin inhibitor, initially prevented formation of the complex, ultimately the irreversible thrombinantithrombin complex was always formed.
\end{abstract}

\section{Abbreviations}

EDC, N-ethyl-N'dimethyl aminopropyl carbodiimide; HBS-EP buffer, $10 \mathrm{mM}$ HEPES, $150 \mathrm{mM}$ $\mathrm{NaCl}, 3.4 \mathrm{mM}$ EDTA and 0.05 polysorbate P20; melagatran, $\mathrm{HOOC}-\mathrm{CH}_{2}-(\mathrm{R})$ cyclohexylglycine-Lazetidine-2-carboxylic acid-para-amidino-benzylamine; NHS, N-hydroxysuccinimide; TAT, thrombinantithrombin complex; PDEA, 2-(2-pyridyldithio)ethaneamine; RU, resonance units; SPR, surface plasmon resonance.

\section{Introduction}

The direct thrombin inhibitor melagatran binds tightly, rapidly and reversibly to the active site of thrombin both in vitro [1-3] and in vivo [4,5]. The serpin antithrombin is the most important natural inhibitor of thrombin in plasma. In the presence of heparin, antithrombin binds rapidly and irreversibly to thrombin and to other coagulation factors. However, antithrombin binds more slowly in the absence of glycosaminoglycans. The anticoagulant activity of heparin is the result of its ability to accelerate

\footnotetext{
*Corresponding author. Tel.: +46 31 7761592; Fax: +46 31 7763736; E-mail: johanna.deinum@ astrazeneca.com.
} 
dramatically $(\approx 1000$-fold $)$ the rate at which antithrombin reacts with thrombin [6]. This accelerating effect of heparin [7] originates by induction of a conformational change in antithrombin [8] and by facilitating "approximation", which requires binding of both thrombin and antithrombin to the same polysaccharide chain [9]. In this in vitro study, the kinetics of the interactions between thrombin and antithrombin in the presence or absence of heparin, and the effect of melagatran on these interactions, were studied by a real-time optical detection method, surface plasmon resonance, SPR, using BIACORE. With this detection method the kinetics of the complex formation of thrombin and antithrombin could be conveniently studied.

SPR relies on the immobilisation or capturing of one of the interacting species, the ligand, onto a dextran-coated gold surface. The second interactant, the analyte, is then injected across the surface, and the interaction of the soluble component with the ligand is observed continuously and directly. Detection depends on changes in the mass concentration of macromolecules at the biospecific interface. The optical phenomenon observed is expressed in resonance units, $\mathrm{RU}$ and a sensorgram is used to present the change in RU over time. The change in RU is proportional with the change in mass at the interface and can thus be used to determine the stoichiometry of the interacting molecules [10].

\section{Materials and methods}

\subsection{Proteins}

Human antithrombin III (antithrombin) was purchased from Athens Research and Technology Inc. (Athens, GE, USA) and human $\alpha$-thrombin (thrombin) was from Sigma Chemicals Co. (St. Louis, MO, USA). Rabbit lung thrombomodulin and recombinant human thrombomodulin were obtained from American Diagnostica Inc. (Greenwich, CT, USA). The following antibodies were used: mouse antihuman thrombin antibody T-5045 (US Biological, Swampscott, MA, USA), mouse anti-human antithrombin antibody HYB230-03 (Statens Seruminstitut, Copenhagen, Denmark), mouse anti thrombin IgG2 A 8810-2006 specific for the thrombin-antithrombin complex (Biogenesis, Poole, UK), and rat anti-mouse antibody (RAMFc) (Biacore AB, Uppsala, Sweden).

\subsection{Compounds}

Hirudin $^{54-65}$ (1468) (Sigma H6769) was used as a marker for the thrombin exosite. The potent thrombin inhibitor melagatran, $\mathrm{HOOC}-\mathrm{CH}_{2}-(\mathrm{R})$ cyclohexylglycine-L-azetidine-2-carboxylic acid-paraamidino-benzylamine (429.5 Da) was obtained from AstraZeneca R\&D, Mölndal, Sweden.

\subsection{Other materials}

Solutions of N-ethyl-N'-(3-dimethyl aminopropyl)-carbodiimide hydrochloride (EDC), N-hydroxysuccinimide (NHS), ethanolamine-HCl were from Biacore AB. Recombinant hirudin (rec desTyr63) was from Ciba Geigy (Basel, Switzerland). Normal heparin (lot B9864C, 5000 units $/ \mathrm{ml}$, average $\mathrm{M}_{\mathrm{r}} 10$ 000) was from Lövens Läkemedel (Malmö, Sweden).

All other solutions were made in deionized water purified by reversed osmosis in an Elgastat Maxima from Elga Ltd (High Wycombe, UK). Before use in the BIACORE the solutions were sterile-filtered through a Millipore $0.22 \mu \mathrm{m}$ filter and degassed for $5 \mathrm{~min}$ with ultrasound in a Labasco Sonorex. NAP5 
columns, used for buffer exchange by gel filtration, were from Amersham Pharmacia Biotech (Uppsala, Sweden).

All BIACORE analyses were made on a BIAcore $2000^{\mathrm{TM}}$ analytical system and carboxymethylated dextran sensorchips, CM5 sensorchips, were from Biacore AB (Uppsala, Sweden). All binding experiments were performed at $25^{\circ} \mathrm{C}$ in the running buffer, HBS-EP ( $\mathrm{pH} 7.4$ ) consisting of $10 \mathrm{mM}$ Hepes, $150 \mathrm{mM} \mathrm{NaCl}, 3 \mathrm{mM}$ EDTA and $0.005 \%$ (w/v) polysorbate 20, obtained from Biacore AB (Uppsala, Sweden) at $25^{\circ} \mathrm{C}$. Except for the binding of hirudin to immobilised thrombin where $30 \mu 1 . \mathrm{min}^{-1}$ was used, the flow rate was $5 \mu 1 \cdot \mathrm{min}^{-1}$.

\subsection{Biacore methods}

\subsubsection{Immobilisation of proteins by amine coupling to CM5 chips}

All proteins were immobilised to CM5 chips using the same amine-coupling procedure. First the dextran surface was activated for $8 \mathrm{~min}$ by a mixture of EDC $(0.2 \mathrm{M})$ and NHS $(0.05 \mathrm{M})$ that had been mixed immediately prior to injection. Then the protein $\left(20-60 \mu \mathrm{g} \cdot \mathrm{ml}^{-1}\right)$ in $10 \mathrm{mM}$ sodium acetate at pH 5 was flowed over the surface for a time period depending on the desired density. Finally, the surface was inactivated by a $5 \mathrm{~min}$ injection of ethanolamine- $\mathrm{HCl}(1 \mathrm{M}) \mathrm{pH}$ 8.5. The surface was then washed for 4 min with $\mathrm{HCl}(20 \mathrm{mM})$ to remove unspecific bound material, followed by a continuous flow of running buffer.

\subsubsection{Binding of antithrombin to captured thrombin or thrombin to captured antithrombin, and the effect of melagatran.}

The different proteins were transferred into HBS-EP buffer by centrifugation though Bio-Spin P6 columns (Bio-Rad Laboratories, Hercules, CA, USA). For the sandwich method first the antibodies $(100 \mathrm{nM})$ were allowed to bind to amine-coupled RAMFc, after which the specific binding protein and then the interacting protein were added. After each cycle the RAMFc surface was regenerated with a $4 \mathrm{~min}$ pulse of $20 \mathrm{mM} \mathrm{HCl}$. Alternatively, the specific antibodies against thrombin, antithrombin or the TAT complex were amine coupled themselves and for each repetitive cycle the surface could be regenerated by 4 min pulse of $20 \mathrm{mM} \mathrm{HCl}$.

Thrombin was captured on the bound anti-human thrombin antibody, by injecting $100 \mathrm{nM}$ thrombin to saturate the antibody. To study the interaction of captured thrombin with antithrombin, antithrombin in the presence or absence of $10 \mu \mathrm{M}$ heparin was injected. All injections were sustained for 4 min. The kinetics of complex formation was explored by repeated injection cycles of varying antithrombin concentrations $(0-2.2 \mu \mathrm{M})$. The effect of melagatran was studied at concentrations between 0 and $1 \mu \mathrm{M}$ added to a $1 \mu \mathrm{M}$ antithrombin solution.

Alternatively, antithrombin was captured on the anti-human antithrombin antibody, HYB230-03, by a 4 min injection of $1 \mu \mathrm{M}$ antithrombin. Repeated cycles of 4 min injections with increasing concentrations of thrombin (0-100 nM) were then run in the presence or absence of $10 \mu \mathrm{M}$ heparin. To study the effect of melagatran, concentrations between 0 and $1 \mu \mathrm{M}$ were added to the $100 \mathrm{nM}$ thrombin solutions.

\subsubsection{Quantification of the thrombin-antithrombin complex by amine coupled mouse antithrombin IgG2 A 8810-2006}

First $100 \mathrm{nM}$ thrombin or $10 \mu \mathrm{M}$ antithrombin were separately flown over the antibody surface to study the specificity of the antibody. Then, different concentrations of TAT, preformed by incubation of thrombin with equimolar concentrations of antithrombin overnight at room temperature, were injected by repeated cycles of $4 \mathrm{~min}$ injections followed by $1 \mathrm{mM} \mathrm{HCl}$, to study the dose response relationship 
of the TAT concentrations with the initial rate of binding. Furthermore, the time dependency of the TAT formation and the effect of heparin and/or melagatran were studied.

\subsubsection{Binding to amine coupled thrombin}

For the analysis of the direct binding of hirudin to immobilised thrombin the assay was performed at $25^{\circ} \mathrm{C}$ at $30 \mu \mathrm{min}^{-1}$. One analytical cycle consisted of $10 \mathrm{~min}$ of buffer flow, followed by $2 \mathrm{~min}$ of hirudin at $0,0.62,1.25,2.5,5,10,20,40,80$ and $160 \mathrm{nM}$ in HBS-EP buffer, and 10 min of buffer flow to follow the dissociation phase. Before the next cycle started the surfaces were regenerated with $30 \mathrm{~s}$ injections of $4 \mathrm{M} \mathrm{MgCl}_{2}$ with $0.1 \mathrm{M}$ sodium acetate at $\mathrm{pH} 4.5$ followed by buffer for $30 \mathrm{~s}$. To quantify the binding of thrombomodulin or antithrombin to amine coupled thrombin these proteins were injected at $10 \mu \mathrm{M}$ in running buffer.

\section{Results}

\subsection{Properties of amine coupled thrombin}

We have previously found that there was a good correlation with the dissociation constants for the binding of a series of active site directed thrombin inhibitors to amine coupled thrombin and the inhibition constants [3] with an expected one-to-one binding stoichiometry. Also hirudin did bind with high affinity to immobilised thrombin, see Fig. 1. A good fit was obtained assuming a bivalent analyte with $\mathrm{Rmax}=137 \mathrm{RU}$ with the main rate constants $k_{\mathrm{a}}=3.8 \times 10^{5} \mathrm{M}^{-1} \mathrm{~s}^{-1}, k_{\mathrm{d}}=8 \times 10^{-5} \mathrm{~s}^{-1}$. However, the association rate constant was lower then expected and apparently hirudin did bind to only approximately $3 / 4$ of the immobilised active thrombin molecules. The sensorgram indicated heterogeneous binding, since hirudin binds both to the active site and the exosite on thrombin. Thus, although the immobilisation of thrombin by amine coupling did not obstruct the immediate environment of the active site, apparently part of the exosite 2 becomes obstructed.

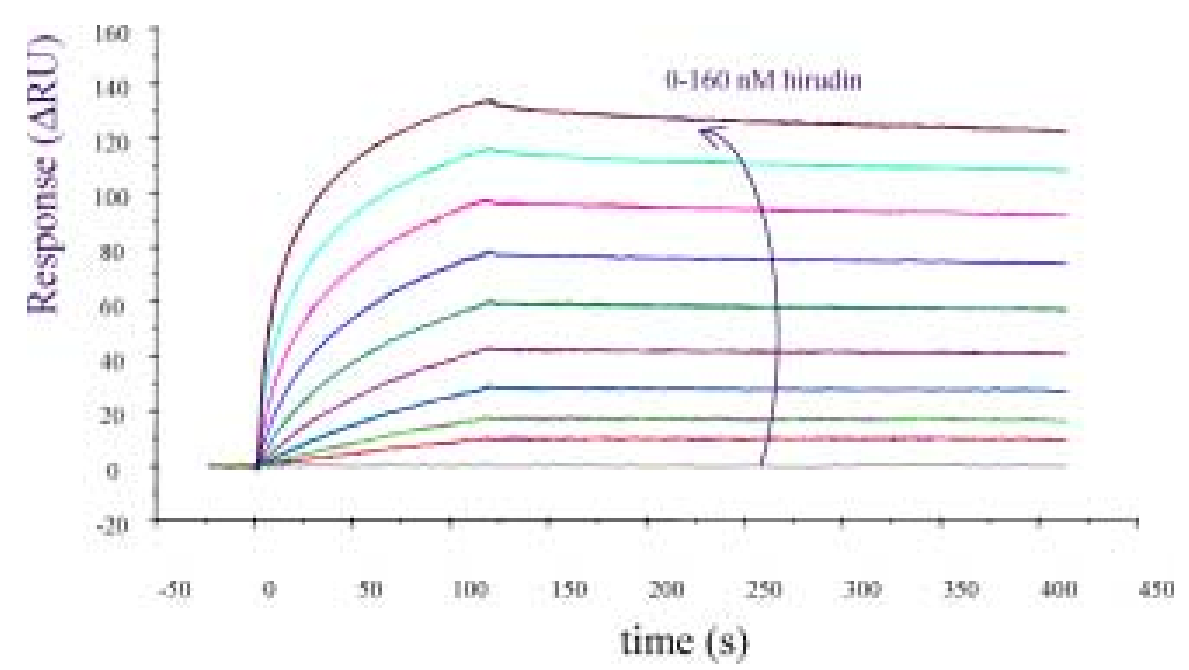

Fig. 1. Binding of hirudin to amine coupled thrombin. Hirudin in running buffer at $0 ., 0.62,1.25,2.5,5,10,20,40,80$ and $160 \mathrm{nM}$ was injected at $30 \mu \mathrm{l} \cdot \mathrm{min}^{-1}$ over $1950 \mathrm{RU}$ amine coupled thrombin. After each cycle the surface was regenerated with $4 \mathrm{M} \mathrm{MgCl}_{2}$ in $0.1 \mathrm{M}$ sodium acetate at $\mathrm{pH} 4.5$ followed by buffer for $30 \mathrm{~s}$. 
Neither antithrombin, nor thrombomodulin could bind to amine-coupled thrombin to any significant amount, not shown. Amine coupling of thrombin in the presence of an excess of hirudin did not make any difference since antithrombin still could not bind. Moreover, not either thrombin could bind to aminecoupled antithrombin. Therefore we used instead antibodies to study complex formation.

\subsection{Thrombin-antithrombin complex captured on antibody}

In principle, a specific antibody with a high affinity for the thrombin-antithrombin (TAT) complex but no affinity for either thrombin or antithrombin could be used to monitor the time course of TAT complex formation and to study the effect of melagatran, since the initial binding rate should be proportional to the concentration of TAT in solution. The purified IgG2A 8806-2006 was therefore immobilised. No binding of either $100 \mathrm{nM}$ thrombin or $10 \mu \mathrm{M}$ antithrombin could be observed; only the preformed TAT complex would bind. However, the binding capacity of this commercial antibody was less than 0.05 mol of TAT per mol of antibody. Preliminary results indicated that when the three components antithrombin with equimolar amounts of thrombin in the absence or presence of melagatran in buffer were mixed immediately before injection, within a short incubation time, TAT was formed in the absence of melagatran, but the presence of melagatran prevented initial complex formation. In contrast, after $2 \mathrm{~h}$ of incubation in the presence of melagatran the irreversible TAT complex was formed. However, since the capacity of this antibody was so low a more detailed study of the time-dependency of the inhibition of complex formation by melagatran could not be made. Therefore, other antibodies, capable of binding both the free components and the TAT complex were used to study the competition of antithrombin with melagatran in binding thrombin.

\subsection{Binding of antithrombin to captured thrombin}

If antibodies are used to capture the proteins (thrombin or antithrombin) instead of using direct immobilisation, repeated binding cycles can be made. However, there is still a risk that the capturing antibody might affect an epitope needed for complex formation. For that reason we have evaluated by BIACORE a large number of commercial antibodies which did not inhibit the activity of thrombin nor its inhibition by antithrombin.

To study the interaction between antithrombin and captured thrombin, an antibody was chosen that had a high affinity for thrombin and could also bind the TAT complex. First, the binding of thrombin to the antibody T-5045 captured on immobilised RAMFc was characterised (not shown). The maximal occupancy of thrombin captured to T-5045 was found to be two mol of thrombin per mol of antibody, with a dissociation constant, $K_{\mathrm{D}}=0.7 \mathrm{nM}$, assuming two independent binding sites. However, the dissociation rate, $k_{\text {off }}$, was not negligible $\left(k_{\text {off }}=8.4 \times 10^{-4} \mathrm{~s}^{-1}\right)$. Interestingly, in the presence of melagatran, a $30 \%$ lower association rate constant, $k_{\mathrm{on}}$, was obtained, and, since $K_{\mathrm{D}}=k_{\text {off }} / k_{\mathrm{on}}$, thus a higher $K_{\mathrm{D}}$. Similar results were obtained with direct immobilisation of T-5045.

A concentration-dependent binding of antithrombin to captured thrombin was found both in the presence or absence of heparin. Examples are shown in Fig. 2 with the sandwich method and Fig. 3 with direct immobilised T-5045. Antithrombin in the presence of $10 \mu \mathrm{M}$ heparin bound to captured thrombin with a higher rate and to a larger extent than when heparin was absent, consistent with the enhancement by heparin of complex formation in solution. The binding that is being observed is a complex function of thrombin dissociating from the antibody at the same time that AT is associating with it. Moreover, there is an apparent change in rate of dissociation of thrombin from the antibody as the concentration of AT increases. Similar results were obtained with both methods of capturing. 


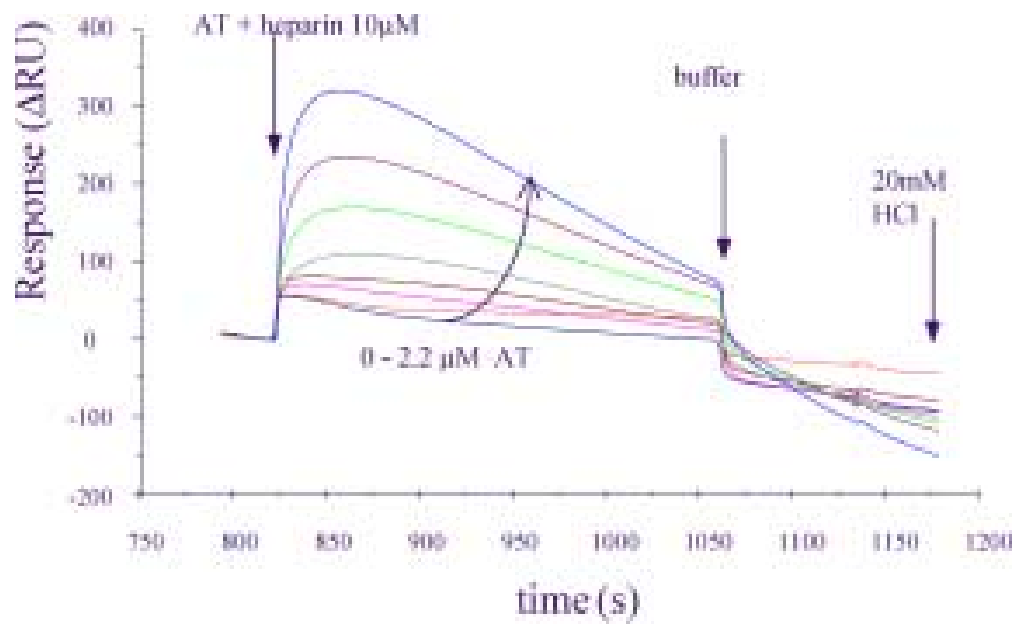

(a)

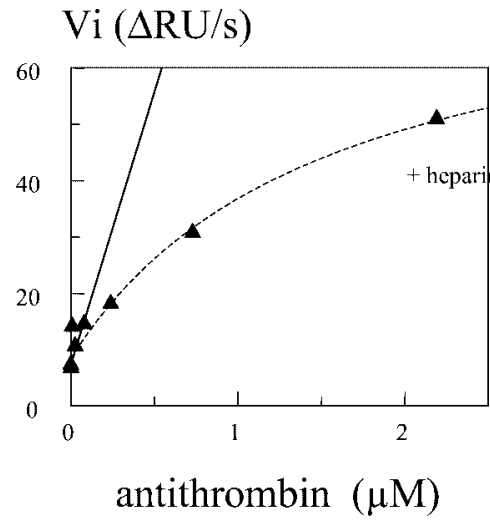

(b)

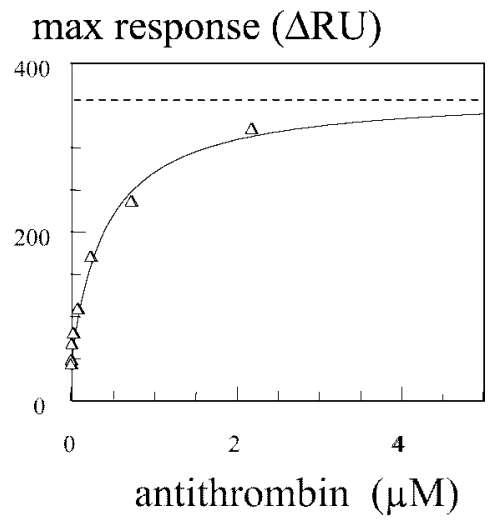

(c)

Fig. 2. Binding of antithrombin, in the presence of heparin, to captured thrombin. (a) Sensorgram. 329 RU thrombin was bound on 1200 RU T-5045 captured on RAM Fc. First, antithrombin concentrations of 0 (dashed trace), 0.001, 0.009, 0.027, 0.081, $0.24,0.73$ and 2.2 (upper trace) $\mu \mathrm{M}$ were injected with $10 \mu \mathrm{M}$ normal heparin. Then, the flow was changed to buffer. After each cycle the RAMFc surface was regenerated with a 4 min pulse of $20 \mathrm{mM} \mathrm{HCl}$. (b) Initial rates. Rapid initial rate of binding of antithrombin to captured thrombin in the presence of heparin, derived from the curves in (a). (c) Max response (RUmax) as a function of the antithrombin concentration in (a).

As shown in Figs 2 and 3 saturation of the available surface of active thrombin occurred before switching back from the flow with antithrombin to the buffer flow. Since the serpin-protease complex becomes irreversible once the final complex has been formed, and the complex dissociated from the antibody, no rebinding of antithrombin is possible and no equilibrium can occur, creating a complex situation. To estimate the amount of bound antithrombin the maximal shift in resonance units, $\mathrm{RU}_{\max }$, was therefore measured at the highest antithrombin concentration from the maximum response during the antithrombin injection after subtraction of the buffer shift, estimated from the shift at (b) in Fig. 2(a). RU $U_{\max }$ was used, assuming that a contribution of heparin to the increase in RU can be neglected. Taking into account that the specific activity of the thrombin $(37 \mathrm{kD})$ was approximately $75 \%(329 \times 0.75=246 \mathrm{RU})$, the extrapolated increase in RU of $312 \mathrm{RU}$ by antithrombin $(58 \mathrm{kD})$, can be calculated assuming one binding site. The saturation level (see Fig. 2(c)) suggests thus approximately $0.8 \mathrm{~mol} / \mathrm{mol}$ complex formation, 


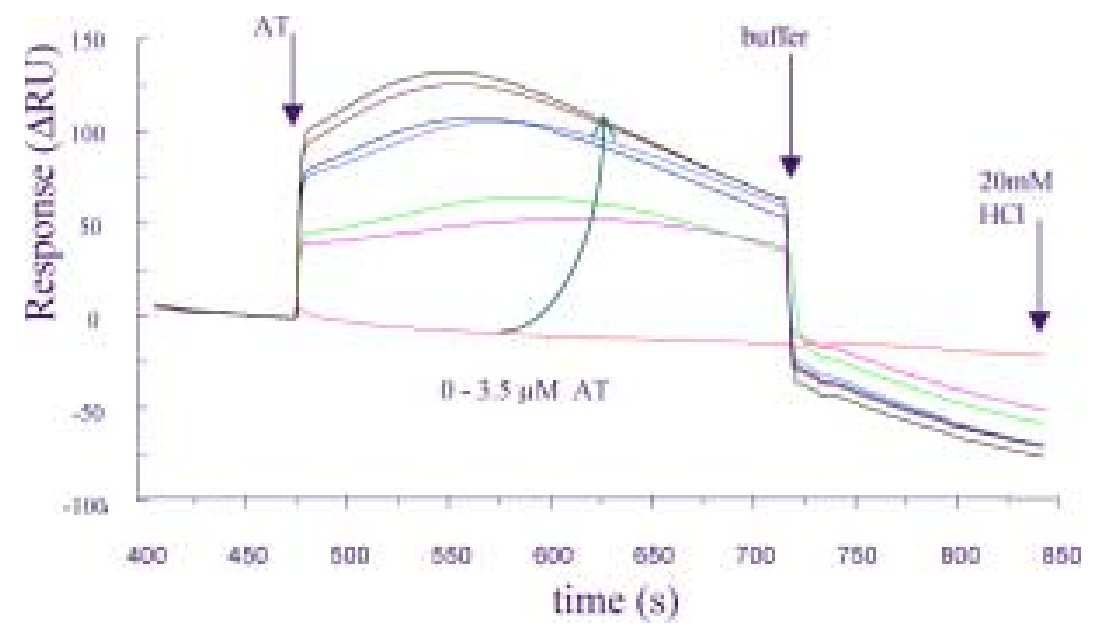

(a)

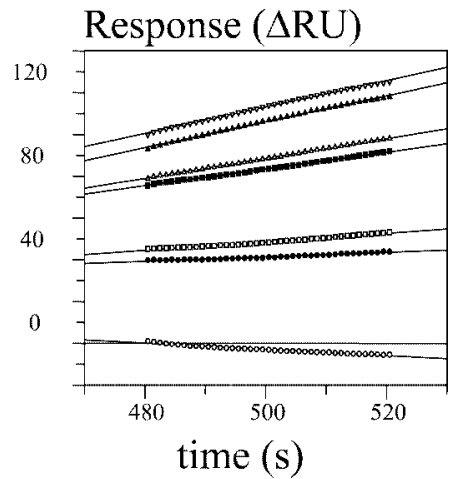

(b)

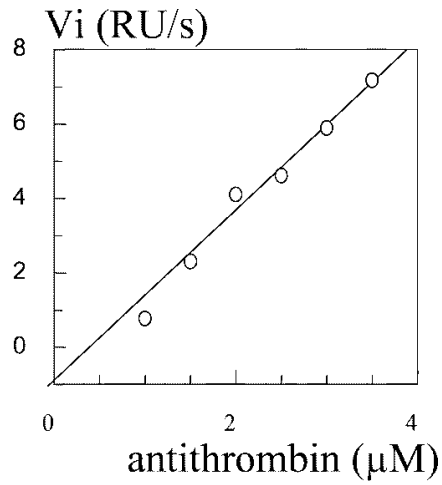

(c)

Fig. 3. Binding of antithrombin to captured thrombin. (a) Sensorgram. 180 RU thrombin was captured on 2800 RU amine-coupled T-5045. First antithrombin at concentrations of 0 (dashed trace) 1, 1.5, 2, 2.5, 3 and 3.5 (upper trace) $\mu \mathrm{M}$ were injected in the absence of heparin. Then the flow was changed to buffer. The sensorgrams are not corrected for the buffer shift. After each cycle the antobody surface was regenerated with a 4 min pulse of $20 \mathrm{mM} \mathrm{HCl}$. (b,c) Initial rates. The initial rate, $V_{\mathrm{i}}$, of binding of antithrombin to captured thrombin in the absence of heparin versus the antithrombin concentration, derived from (a).

which is near the theoretical one-to-one ratio. This ratio confirms the assumption that heparin remains not bound to the final complex between antithrombin and thrombin.

From the initial rate, $\mathrm{dRU} / \mathrm{d} t$, of complex formation (Fig. 2(b)) an estimate of the association rate constant, $k_{\mathrm{a}}$, can be made, according to [11,12]:

$$
V_{\mathrm{i}}=\mathrm{dRU} / \mathrm{d} t=k_{\mathrm{a}} \times \mathrm{RU}_{\max } \times[\text { analyte }],
$$

where the analyte is the component in the flow, id est antithrombin. The initial binding rate in the presence of heparin, $V_{\mathrm{i}}$, was found not to be linearly dependent on the antithrombin concentration (see Fig. 2(b)), suggesting mass transport limitation. From the slope to the curve in Fig. 2(b), a limiting slope of $135 \mathrm{RU} \mu \mathrm{M}^{-1} \mathrm{~s}^{-1}$ was calculated and, with $\mathrm{RU}_{\max }=312 \mathrm{RU}$, the second-order rate constant in the presence of heparin, $k_{\mathrm{a}}$, can thus be estimated to be $\geqslant 0.4 \times 10^{6} \mathrm{M}^{-1} \mathrm{~s}^{-1}$. A similar estimate was found using amine coupled T-5045. 
Upon injection of $3.5 \mu \mathrm{M}$, the highest concentration of antithrombin used in the absence of heparin, apparently less antithrombin was bound to thrombin (see Fig. 3), since considerably slower rates were found than in the presence of heparin (Fig. 2). Be aware that the first rapid change in RU originated from the difference in refraction index of the buffer, since the sensorgrams in Figs 2 and 3 have not been corrected for the buffer shift [2]. At $2.2 \mu \mathrm{M}$ antithrombin, the highest concentration used in the absence of heparin, only $70 \mathrm{RU}$ of antithrombin bound to the thrombin surface of $180 \mathrm{RU}$. Thus the molar ratio was $1: 3$ after correcting for the $75 \%$ specific activity of thrombin, which suggests that the maximal antithrombin concentration used was too low to achieve saturation before the TAT complex dissociated.

The initial rate in the absence of heparin, $V_{\mathrm{i}}$, was found to be linearly dependent on the antithrombin concentration (see Fig. 2(b)), with a slope of $2.4 \mathrm{RU} \mu \mathrm{M}^{-1} \mathrm{~s}^{-1}$. With $\mathrm{RU}_{\max }=280 \mathrm{RU}$, the second-order rate constant in the absence of heparin, $k_{\mathrm{a}}$, can thereby be estimated to be $9 \times 10^{3} \mathrm{M}^{-1} \mathrm{~s}^{-1}$. A linear dependency was also found with the sandwich method, not shown.

The more rapid dissociation from T-5045 of the thrombin-antithrombin complex compared to thrombin did not depend on the interaction between T-5045 and RAMFc, since similar results were obtained both with amine coupled T-5045 and T-5045 captured on RAMFc.

\subsection{Effect of melagatran on binding of antithrombin to thrombin}

With increasing concentrations of melagatran (Fig. 4) with $1 \mu \mathrm{M}$ antithrombin in the presence of $10 \mu \mathrm{M}$ heparin and thrombin captured on T-5045 on immobilised RAMFc, the $\Delta \mathrm{R} \mathrm{U}_{\max }$ dose-dependently decreased. With higher concentrations of melagatran (see Fig. 4), less complex is formed and the dissociation curves became less steep because the $k_{\text {off }}$ for the dissociation from the thrombin-antibody surface decreased.

Since the complex started to dissociate during the injection of antithrombin, an accurate analysis of the intermediate complex could not be made. Therefore, the effect of melagatran was evaluated both from the initial rate, $V_{\mathrm{i}}=\mathrm{dRU} / \mathrm{d} t$, and from the final part of the injection (shift in RU). From the IC50 curve for melagatran (Fig. 3(b)), approximately the same values were found, $20 \mathrm{nM}$ and $30 \mathrm{nM}$, respectively, using the two approaches at an antithrombin concentration of $1 \mu \mathrm{M}$.

\subsection{Binding of thrombin to captured antithrombin}

Figure 5 shows the binding of thrombin, at different concentrations, to antithrombin captured by a RAMFc-bound antibody, HYB230-03. HYB230-03 was the only commercial monoclonal antibody against antithrombin we could find that allowed thrombin to bind to captured antithrombin. Unfortunately, the dissociation rate was considerable. Direct amine coupling of HYB230-03 did not improve the stability of the antibody-antithrombin surface. In contrast to T-5045 (the antibody against thrombin), this particular antibody against antithrombin, HYB230-03, had higher affinity for TAT than for antithrombin. As a consequence, the surface ceased to decay when thrombin bound to antithrombin, which again created a complex situation, explaining the slightly sigmoidal binding curve.

When the initial reaction rate, $V_{\mathrm{i}}$, was plotted against the thrombin concentration (Fig. 5(b)) an almost perfect linear relationship between the initial slope of the binding curves and the thrombin concentration was found, $170 \mathrm{RU} \mu \mathrm{M}^{-1} \mathrm{~s}^{-1}$. With the highest concentration of thrombin used, $100 \mathrm{nM}$, approximately $420 \mathrm{RU}$ was obtained, suggesting binding of $0.6 \mathrm{~mol}$ of thrombin per mol of captured antithrombin. The theoretical $\mathrm{RU}_{\max }$ should be $700 \mathrm{RU}$ for a one-to-one complex. Applying Eq. (1), the second-order rate constant in the presence of heparin is estimated to be $k_{\mathrm{a}}=0.24-0.4 \times 10^{6} \mathrm{M}^{-1} \mathrm{~s}^{-1}$, equivalent to the 


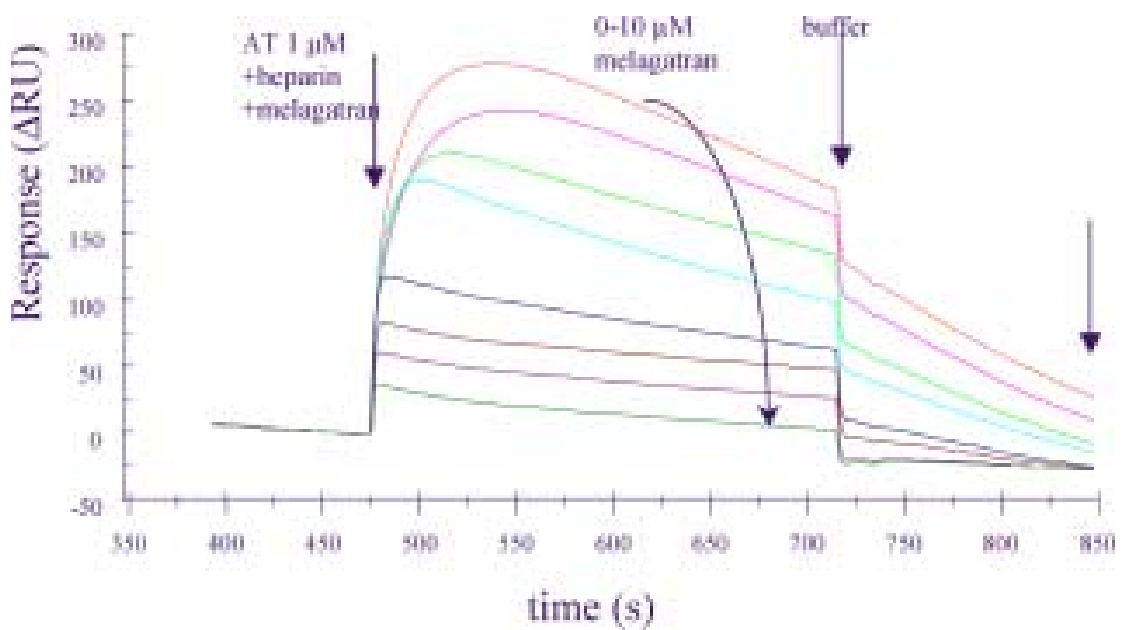

(a)

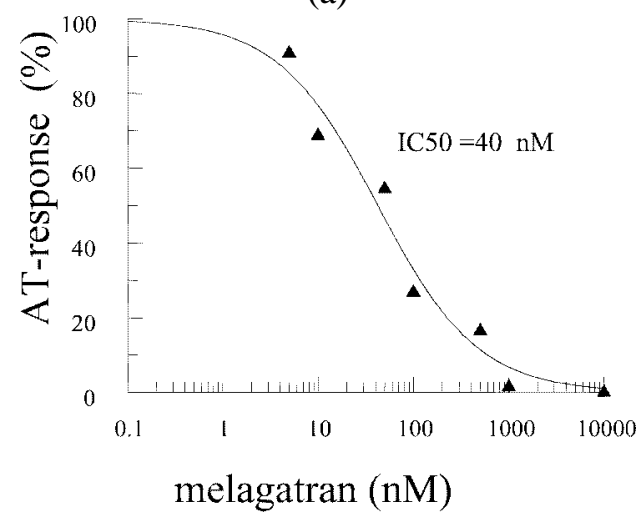

(b)

Fig. 4. Effect of melagatran on binding of antithrombin to captured thrombin. (a) Sensorgram. 200 RU thrombin was captured on $2800 \mathrm{RU}$ amine-coupled T-5045. First $1 \mu \mathrm{M}$ antithrombin with $10 \mu \mathrm{M}$ heparin in the presence of melagatran at increasing concentrations of 0 (dashed trace) $0.005,0.01,0.05,0.1,0.5,1$ and 10 (lower trace) $\mu \mathrm{M}$ were injected. Then the flow was changed to buffer. After each cycle the antbody surface was regenerated with a 4 min pulse of $20 \mathrm{mM} \mathrm{HCl}$. (b) Dose-effect of melagatran. $\triangle \mathrm{RU}$ of antithrombin was measured from the initial rate (closed symbols) and from the shift in RU before change to buffer, normalised for the decaying thrombin surface (open symbols) in (a).

value obtained from the binding of antithrombin to thrombin in Fig. 2. This value might be underestimated because of mass transport limitations and correction for the decaying surface.

The linear dependency of the binding rate on the thrombin concentration (Fig. 5) provided a method to determine the concentration of free and active thrombin in solution that can react with antithrombin, independent of the presence of inactive or inhibited thrombin.

The binding of $100 \mathrm{nM}$ thrombin to antithrombin dos-dependently decreased when different concentrations of melagatran were injected together with thrombin (Fig. 6). A nearly linear relationship was found between the initial slope and the melagatran concentration (see Fig. 6(b)). The linear fit showed that a slight molar excess of melagatran totally inhibited complex formation of thrombin with antithrombin. Thrombin $(100 \mathrm{nM})$ and melagatran were pre-incubated. Thus, with the high concentration of thrombin used, no information about the inhibition constant, $K_{\mathrm{i}}$, can be obtained from this type of experiment. As expected, active-site-blocked thrombin can no longer bind to antithrombin. 


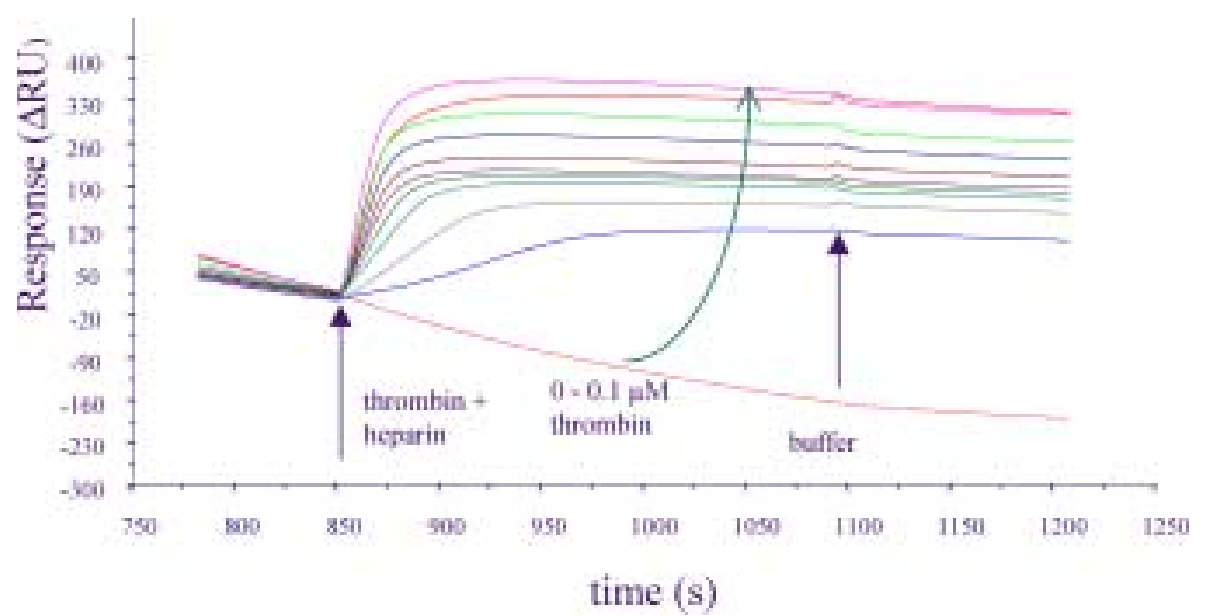

(a)

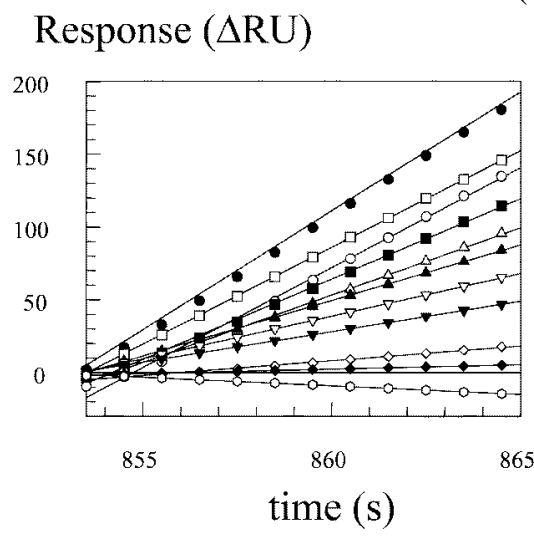

(b)

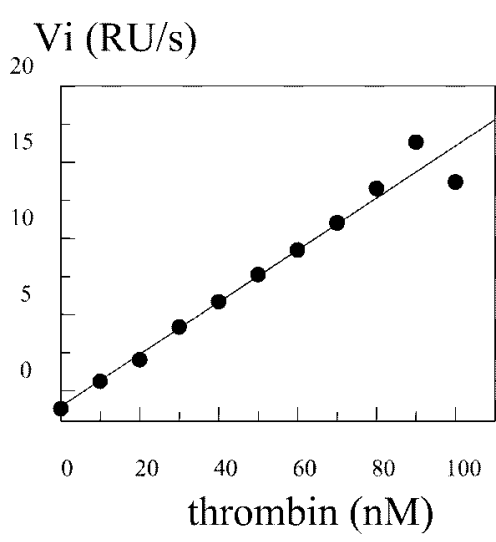

(c)

Fig. 5. Binding of thrombin, in the presence of heparin, to captured antithrombin. (a) Sensorgram. 1100 RU antithrombin was captured by 2600 RU HYB230-03 on amine coupled RAM-Fc. At time $=850 \mathrm{~s}$, different concentrations of thrombin $(0,10$, $20,30,40,50,60,70,80,90$ and $100 \mathrm{nM})$ in the presence of $10 \mu \mathrm{M}$ normal heparin were injected. At time $=1080 \mathrm{~s}$ buffer was injected. The dashed trace did not contain thrombin. After each cycle the RAMFc surface was regenerated with a 4 min pulse of $20 \mathrm{mM} \mathrm{HCl}$. (b) Left panel: Binding of thrombin, in the presence of heparin, to antithrombin captured on HYB230-03. Right panel: Initial rates as a function of the thrombin concentration, data from (a).

\section{Discussion}

The interaction between another serpin, immobilised plasminogen activator inhibitor type 1 (PAI-1), and the protease tissue plasminogen activator (tPA) has previously been characterised successfully by BIACORE [13]. A prerequisite for this method is that the interacting components are not affected by the immobilisation. We have previously found $[2,3]$ that the active site of thrombin after immobilisation by amine coupling remains fully accessible to reversible low-molecular-mass active site inhibitors such as melagatran [1-3]. However, immobilisation of the target protein always includes a risk that epitopes important for the interaction become obscured. Although hirudin, which binds both to the anion exosite 1 and the active site of thrombin, still could bind $\left(K_{\mathrm{D}} \leqslant 1 \mathrm{pM}\right)$ the approximated association rate constant is less than expected from solution and the stoichiometry is one-to-two. On the surface of thrombin there are a large number of lysine residues and three residues, K36, K60 and K149 are near exosite 1 [14]. 


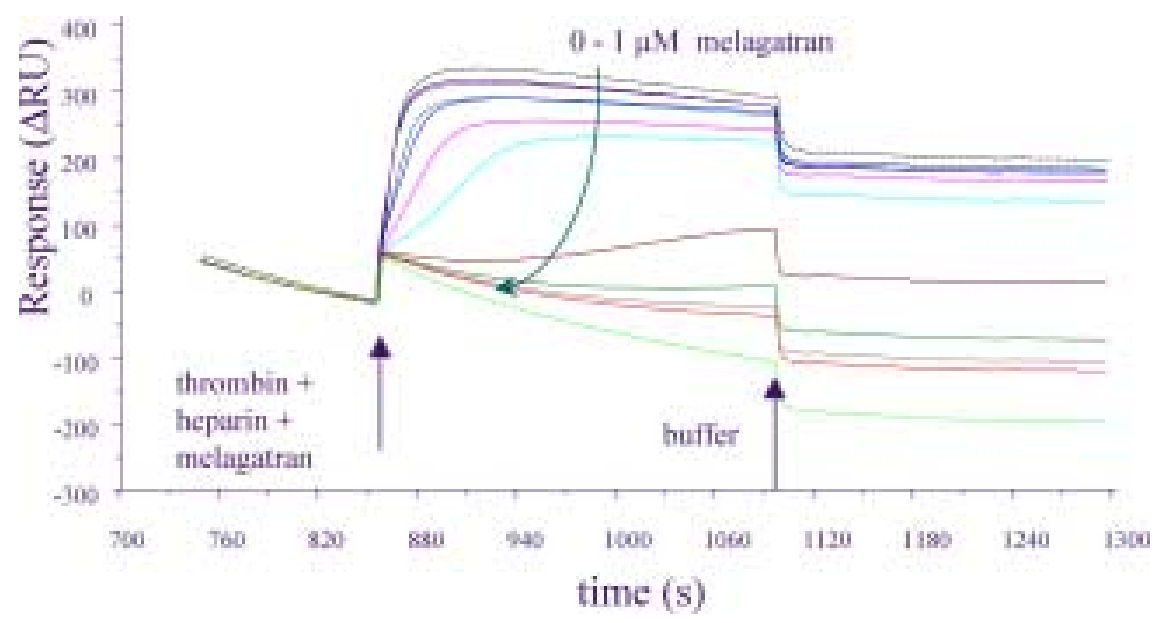

(a)

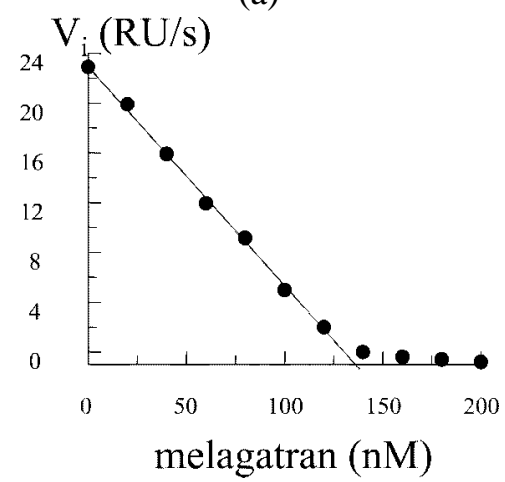

(b)

Fig. 6. Effect of melagatran on binding of thrombin, in the presence of heparin, to captured antithrombin. (a) Sensorgram 900 RU antithrombin was captured on 2400 RU HYB230-03 on amine coupled RAM Fc. At time $=850 \mathrm{~s}, 100 \mathrm{nM}$ thrombin with $10 \mu \mathrm{M}$ normal heparin and different concentrations of melagatran $(0,20,40,60,80,100,120,140,160,180,200,1000 \mathrm{nM})$, were injected. The upper dashed trace contained thrombin and heparin but no melagatran. At time $=1080 \mathrm{~s}$ buffer was injected. The lowest, dashed trace, contained only buffer. After each cycle the RAMFc surface was regenerated with a 4 min pulse of 20 $\mathrm{mM} \mathrm{HCl}$. (b) Initial rate. The effect of melagatran on the initial association rate with $100 \mathrm{nM}$ thrombin, data from (a).

However, by amine coupling apparently not all molecules are coupled identically, permitting hirudin to bind to approximately $3 / 4$ of the number of the immobilised active thrombin molecules. Moreover, neither antithrombin, nor thrombomodulin did bind to any significant extent, confirming that exosite 1 is affected.

In contrast to the complex of thrombin with melagatran, the complex of thrombin with the serpin antithrombin is (practically) irreversible [15]. Consistent with this, after complex formation, the antithrombin or thrombin surface cannot be regenerated. For the study of the interaction between antithrombin and thrombin, direct amine coupling of one of the interacting components is thus not feasible. An antibody is therefore needed to capture the proteins without interfering with the complex formation and giving the possibility to run many cycles of binding and dissociation.

To study the interaction between thrombin and antithrombin and the effect of melagatran on complex formation, a range of commercial monoclonal antibodies was tested. Surprisingly, only a few of these antibodies bound thrombin or antithrombin with high affinity. Only the two monoclonal antibodies used 
in the present study were found to have a high specificity and affinity for the proteins. Furthermore, only a few antibodies bound both to thrombin or antithrombin and to the complex of thrombin and antithrombin, TAT.

Unfortunately, even the T-5045 antibody was not ideal for capturing thrombin, because of the relatively high dissociation rate of thrombin from the antibody, $k_{\text {off }}=8.4 \times 10^{-4} \mathrm{~s}^{-1}$. The consequence was that antithrombin bound to a decaying thrombin surface. Moreover, the TAT complex dissociated even more rapidly from the coupled antibody T-5045. Conventional data evaluation was therefore not possible, because the dissociation in the presence of antithrombin reflected the dissociation of the TAT complex from the antibody as well as the dissociation between thrombin and its inhibitor. Neither direct-coupling of the antibody nor lowering the temperature to $17^{\circ} \mathrm{C}$ solved these problems. This effect of antithrombin on the interaction between thrombin and the antibody thus confirmed the hypothesis that a profound conformational change in the protease occurs upon complex formation with the serpin [16,17]. In the presence of melagatran, a $30 \%$ lower association rate constant, $k_{\mathrm{on}}$, was obtained for the binding of thrombin to the antibody. The effect of melagatran on the affinity of thrombin for the antibody against thrombin also suggests that occupancy of the active site with a small molecule can induce a conformational change in thrombin, consistent with the change in the intrinsic fluorescence of thrombin [1].

The general appearance of the association phase when antithrombin bound to thrombin was complicated, since the surface became saturated before changing to buffer flow, and the formed complex started to dissociate. Within the concentration interval tested, the $\mathrm{RU}_{\max }$ is still dependent on the antithrombin concentration (see Fig. 2). The higher dissociation rate of the TAT complex from the antibody compared to that of thrombin implies that the antibody had a lower affinity for the complex than for thrombin. Moreover, we have to consider the presence of two or three forms of complex between thrombin (E) and antithrombin (I), as the serpin first binds in a looser complex, EI, before the final formation of the irreversible TAT complex, E-I, in the general scheme given below:

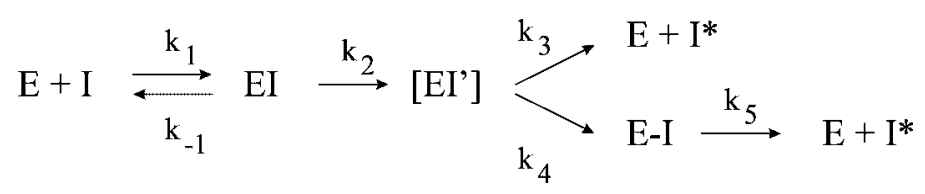

When the system was reversed, i.e., thrombin bound to antithrombin that was captured by HYB230-03, the binding curves looked somewhat different. The dissociation rate of antithrombin was again relatively high which meant that thrombin was binding to a decaying antithrombin surface. This would have been easy to correct for by reference subtraction if the TAT complex that formed had the same dissociation rate. Instead the TAT complex bound to the antibody HYB230-03 with a much higher affinity than antithrombin itself. Since complex formation occurs through the whole binding phase, normal kinetic evaluation was not possible.

Melagatran was included in the experiments to determine whether the interaction between thrombin and antithrombin was affected. It has been shown previously that another synthetic thrombin inhibitor, argatroban, retarded the time-dependent inactivation of thrombin [18]. As expected, initial complex formation was inhibited by quite low concentrations of melagatran. At the temperature used, the $K_{\mathrm{i}}$ for the reversible binding of melagatran to thrombin is approximately $2 \mathrm{nM}$ [1]. If we assume a competition between melagatran and antithrombin in binding to the active site of thrombin, then:

$$
\mathrm{IC50}=K_{\mathrm{i}}\left(1+1000 / K_{\mathrm{D}}\right) .
$$


Substitution of the $K_{\mathrm{i}}(2 \mathrm{nM})$ and the IC50 $(40 \mathrm{nM})$ then provides an estimated value of $50 \mathrm{nM}$ for the overall $K_{\mathrm{D}}$ of antithrombin and thrombin in the formation of the primary, reversible complex, EI (see above). This $K_{\mathrm{D}}$ value for the interaction between antithrombin and thrombin estimated by the BIACORE technique was similar to the value of $90 \mathrm{nM}$ reported using other techniques [19].

We can conclude that in the competition between melagatran and antithrombin for binding to captured thrombin, the association rate of melagatran must be higher than that of antithrombin, because relatively low melagatran concentrations prevented complex formation with antithrombin. The presence of melagatran with the preformed TAT complex did not affect the affinity of the complex for either HYB230-03 or T-5045 antibody (data not shown). This confirms that melagatran cannot dissociate the final irreversible complex between antithrombin and thrombin.

Although these antibodies are far form perfect useful and reliable information can be obtained. Furthermore, we do not need to simulate and evaluate all the binding and dissociation events between thrombin and antithrombin (AT) and the antibodies. A different approach to data evaluation was taken. The initial, linear part of the curves was plotted and the initial rates were calculated from the slopes. These slopes were then plotted against the concentration of antithrombin, and a linear relation was found (as shown for example in Figs 3 and 5), from which the association rate constants were estimated. In previous stopped flow studies the $k_{\mathrm{a}}$ for binding of the reversible inhibitor, melagatran, to thrombin has been determined to be approximately $30 \mu \mathrm{M}^{-1} \mathrm{~s}^{-1}$. Literature values show that the overall association rate for antithrombin to thrombin in solution, in the absence of heparin, is $14 \mathrm{mM}^{-1} \mathrm{~s}^{-1}$, but in the presence of heparin is $15 \mu \mathrm{M}^{-1} \mathrm{~s}^{-1}[20,21]$. In our BIACORE experiments a $k_{\mathrm{a}}$ of $9 \mathrm{mM}^{-1} \mathrm{~s}^{-1}$ was obtained from the initial rate of binding in the absence of heparin. In the presence of heparin a $k_{\mathrm{a}} \geqslant 0.4 \mu \mathrm{M}^{-1} \mathrm{~s}^{-1}$ was found, as deduced both from the captured antithrombin and the captured thrombin assays. The latter value might, though, be underestimated by the phenomenon of mass transport limitations [22,23]. However, a limiting value of the association rate can also be estimated from the fact that melagatran with a $k_{\mathrm{a}}=30 \mu \mathrm{M}^{-1} \mathrm{~s}^{-1}$ [1] did compete in nanomolar concentrations with $1 \mu \mathrm{M}$ antithrombin. This implies that the $k_{\mathrm{a}}$ for the association of antithrombin with captured thrombin had to be less than $1 \mu \mathrm{M}^{-1} \mathrm{~s}^{-1}$ in the buffer used, and suggests that the reported $k_{\mathrm{a}}[20,21]$ in solution might not be valid under the conditions used in this investigation.

Measurement of the formed TAT complex in solution in the same buffer used for the BIACORE experiment, in the presence of melagatran and heparin, also confirmed the results obtained with the captured proteins. Equimolar concentrations of melagatran effectively inhibited the initial complex formation of thrombin with antithrombin. However, in solution, although melagatran is a very potent inhibitor, it is a reversible inhibitor of thrombin, by forming the irreversible TAT complex, and antithrombin will eventually bind all the available thrombin; it is just a matter of time. In vivo, the clearance of the complex between the serpin and the proteinase from the circulation is about 10-fold faster than that of the nonreacted serpin [24]. We conclude, therefore, that, because melagatran initially prevents TAT complex formation, it is not only a potent, reversible inhibitor of thrombin, but it also acts as a protective agent for antithrombin, preventing consumption of the serpin.

Although melagatran, a reversible thrombin inhibitor, initially prevented formation of the complex, ultimately the irreversible thrombin-antithrombin complex was always formed. One should also be aware of the possibility that measurement of the concentration of the thrombin-antithrombin complex in plasma samples in the presence of a rapid-binding thrombin inhibitor might underestimate the amount of generated thrombin. 


\section{References}

[1] T. Nilsson, A. Sjoling-Ericksson, J. Deinum, The mechanism of binding of low-molecular-weight active site inhibitors to human alpha-thrombin, J. Enzym. Inhib. 13 (1998), 11-29.

[2] R. Karlsson, M. Kullman-Magnusson, M. D. Hamalainen, A. Remaeus, K. Andersson, P. Borg, E. Gyzander and J. Deinum, Biosensor analysis of drug-target interactions: Direct and competitive binding assays for investigation of interactions between thrombin and thrombin inhibitors, Anal. Biochem. 278 (2000), 1-13.

[3] J. Deinum, L. Gustavsson, E. Gyzander, M. Kullman-Magnusson, A. Edstrom and R. Karlsson, A thermodynamic characterization of the binding of thrombin inhibitors to human thrombin, combining biosensor technology, stopped-flow spectrophotometry, and microcalorimetry, Anal. Biochem. 300 (2002), 152-162.

[4] M. Elg, D. Gustafsson and J. Deinum, The importance of enzyme inhibition kinetics for the effect of thrombin inhibitors in a rat model of arterial thrombosis, Thrombosis \& Haemostasis 78 (1997), 1286-1292.

[5] D. Gustafsson, T. Antonsson, R. Bylund, U. Eriksson, E. Gyzander, I. Nilsson, M. Elg, C. Mattsson, J. Deinum, S. Pehrsson, O. Karlsson, A. Nilsson and H. Sorensen, Effects of melagatran, a new low-molecular-weight thrombin inhibitor, on thrombin and fibrinolytic enzymes, Thrombosis \& Haemostasis 79 (1998), 110-118.

[6] R. Jordan, D. Beeler and R. Rosenberg, Fractionation of low molecular weight species and their interaction with antithrombin, J. Biol. Chem. 254 (1979), 2902-2908.

[7] S. Olson and I. Bjork, Predominant contribution of surface approximation to the mechanism of heparin acceleration of the antithrombin-thrombin reaction. Elucidation from salt concentration effects, J. Biol. Chem. 266 (1991), 6353-6364.

[8] J.C. Whisstock, N.P. Pike, L. Jin, R. Skinner, X.Y. Pei, R.W. Carrell and A.M. Lesk, Conformational changes in serpins: II. The mechanism of activation of antithrombin by heparin, J. Molecular Biology 301 (2000), 1287-1305.

[9] T. Laurent, A. Tengblad, L. Thunberg, M. Höök and U. Lindahl, The molecular-weight-dependence of the anticoagulant activity of heparin, Biochem. J. 175 (1978), 691-696.

[10] E. Stenberg, B. Persson, H. Roos and C. Urbanniczky, Quantitative detrmination of surface concentration of protein with surface plasmon resonance by using radiolabelled proteins, J. Colloid Interface Sci. 143 (1991), 513-526.

[11] P.R. Edwards and R.J. Leatherbarrow, Determination of association rate constants by an optical biosensor using initial rate analysis, Anal. Biochem. 246 (1997), 1-6.

[12] R. Leatherbarrow and P. Edwards, Analysis of molecular recognition using optical biosensors, Curr. Opin. Chem. Biol. 3 (1999), 544-547.

[13] P. Björquist, M. Brohlin, J. Ehnebom, M. Ericsson, C. Kristiansen, G. Pohl and J. Deinum, Plasminogen activator inhibitor type-1 interacts exclusively with the proteinase domain of tissue plasminogen activator, Biochim. Biophys. Acta 1209 (1994), 191-202.

[14] W. Bode and M.T. Stubbs, Spatial structure of thrombin as a guide to its multiple sites of interaction, Seminars in Thrombosis and Hemostasis 19 (1993), 321-333.

[15] T. Myles, F.C. Church, H.C. Whinna, D. Monard and S.R. Stone, Role of thrombin anionbinding exosite-I in the formation of thrombin-serpin complexes, J. Biol. Chem. 273 (1998), 31 203-31 208.

[16] G. Villanueva and I. Danishefsky, Conformational changes accompanying the binding of antithrombin III to thrombin, Biochemistry 18 (1979), 810-817.

[17] J. Dawes, K. James and D.A. Lane, Conformational change in antithrombin induced by heparin, probed with a monoclonal antibody against the 1C/4B region, Biochemistry 33 (1994), 4375-4383.

[18] A. Hijikata-Okunomiya, S. Okamoto and K. Wanaka, Effect of a synthetic thrombin-inhibitor MD805 on the reaction between thrombin and plasma antithrombin-III, Thromb. Res. 59 (1990), 967-977.

[19] Z.-R. Gan, Y. Li, Z. Chen, S.D. Lewis, J.A. Shafer, Identification of basic amino acid residues in thrombin essential for heparin-catalyzed inactivation by antithrombin III, J. Biol. Chem. 269 (1994), 1301-1305.

[20] S.T. Olson and J.D. Shore, Demonstration of a two-step reaction mechanism for inhibition of alpha-thrombin by antithrombin III and identification of the step affected by heparin, J. Biol. Chem. 257 (1982), 14 891-14 895.

[21] S.T. Olson and I. Bjork, Regulation of thrombin activity by antithrombin and heparin, Semin. Thromb. Hemost. 20 (1994), 373-409.

[22] D.G. Myszka, X. He, M. Dembo, T.A. Morton and B. Goldstein, Extending the range of rate constants available from BIACORE: interpreting mass transport-influenced binding data, Biophys. J. 75 (1998), 583-594.

[23] P. Schuck, Reliable determination of binding affinity and kinetics using surface plasmon resonance biosensors, Curr. Opin. Biotechnol. 8 (1997), 498-502.

[24] H. Fuchs, M. Shifman and S. Pizzo, In vivo catabolism of $\alpha 1$-proteinase inhibitor, antithrombin III-thrombin and a2-macroglobulin-methylamine, Biochim. Biophys. Acta 716 (1982), 151-157. 


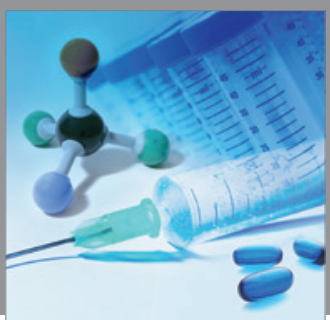

International Journal of

Medicinal Chemistry

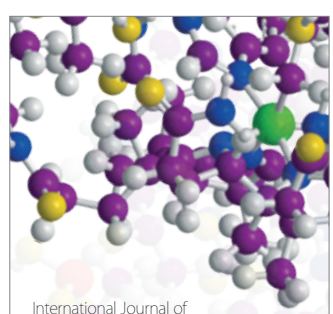

Carbohydrate Chemistry

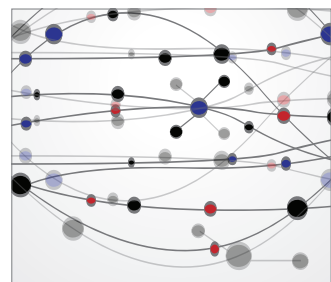

The Scientific World Journal
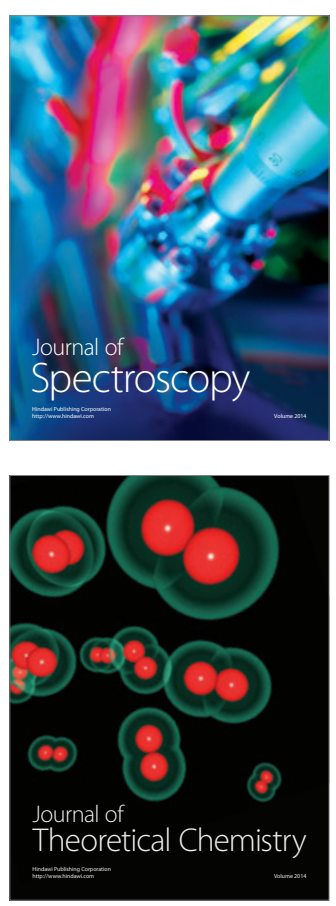
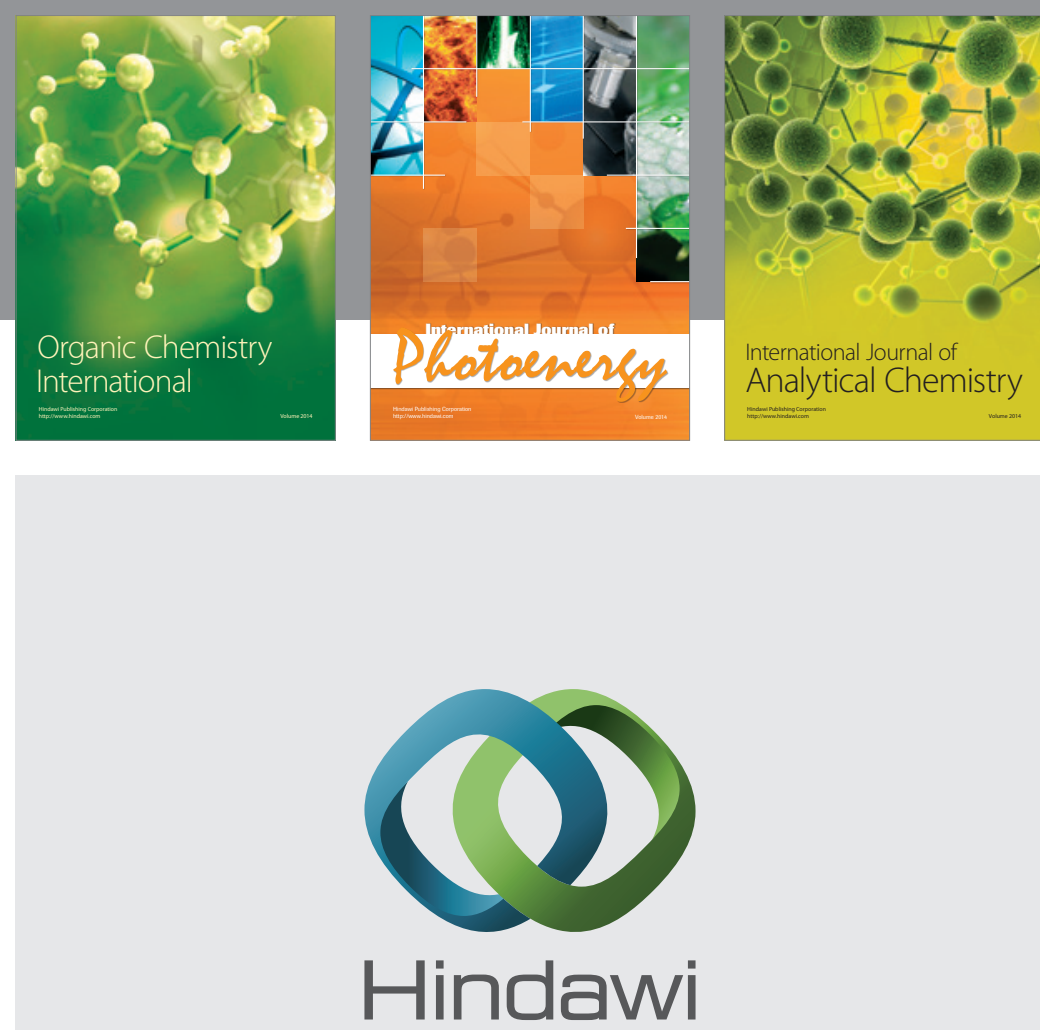

Submit your manuscripts at

http://www.hindawi.com
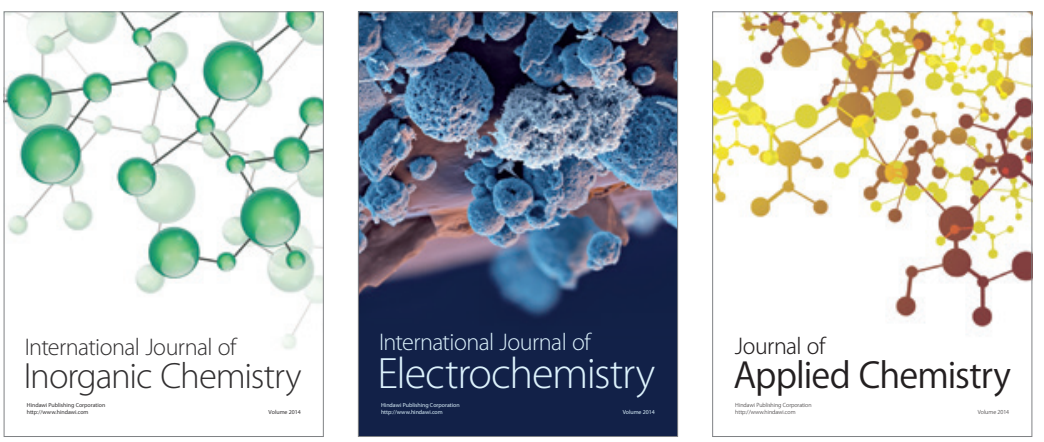

Journal of

Applied Chemistry
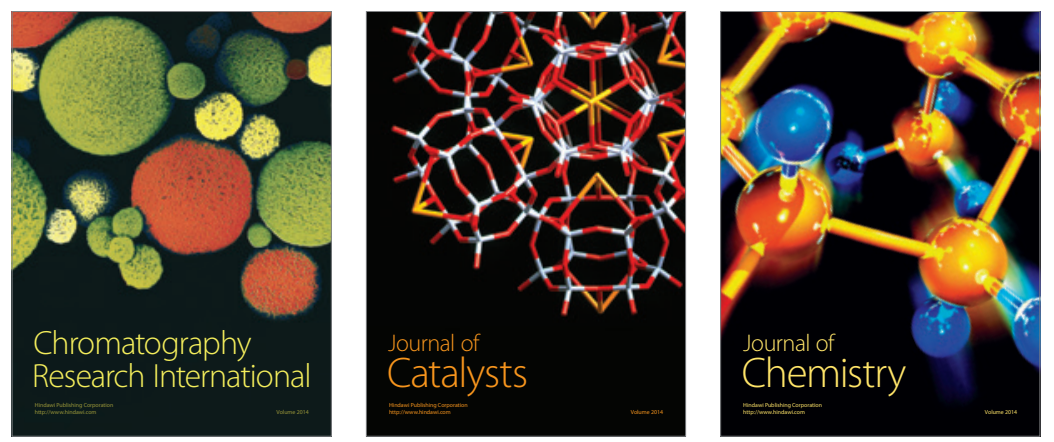
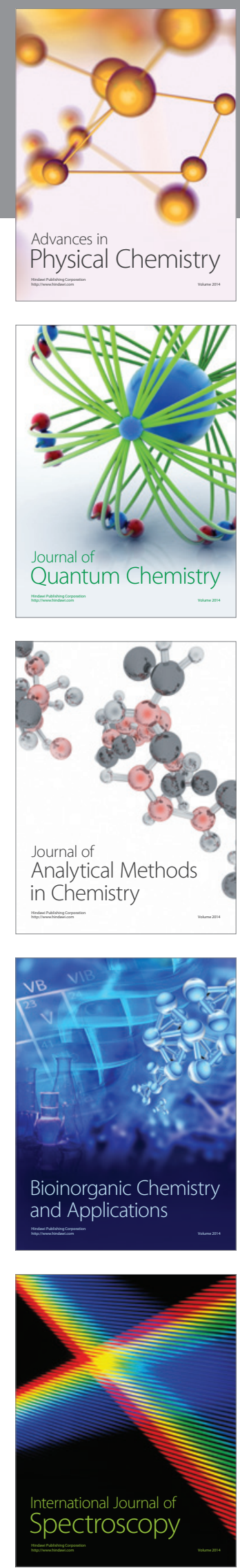